\title{
Respostas agudas e tardias da creatina quinase após duas configurações distintas de treinamento resistido
}

Acute and late creatine kinase responses after two distinct configurations of resisted training

Respuestas agudas y tardías de creatina cinasa después de dos configuraciones distintas de entrenamiento resistente

\author{
Lucas Dantas Maia Forte ${ }^{2,3}$ \\ Renan Ramalho Paiva ${ }^{1}$
}

Claudio Luiz de Souza Meireles ${ }^{1}$

\section{Resumo}

O presente estudo investigou o efeito de duas sessões de treinamento resistido (hipertrofia vs resistência) sobre os níveis de dano muscular 24 e 48 hs pós-exercício. Seis homens jovens foram submetidos a dois protocolos de TR para o corpo inteiro, sendo um protocolo de treinamento resistido para hipertrofia (TRH; 75\%1-RM, 8-12 repetições) e um protocolo de treinamento resistido para resistência (TRR; 15\%1-RM, 50-60 repetições). Foram encontradas diferenças estatisticamente significativas $(p<0,05)$ nas concentrações sanguíneas de CK entre os valores de pré- e 24hs pós-exercício no TRH. Não houve diferenças entre os grupos ou entre os resultados dos diferentes momentos de coleta em TRR. Conclui-se que o protocolo de TRH induz a um aumento estatisticamente significativo na expressão de CK 24hs após sua aplicação e que essa expressão não se mantém elevada $48 \mathrm{hs}$ a utilização desse protocolo. Finalmente, o protocolo de TRR não demonstrou diferenças concentrações sanguíneas de CK.

Palavras - chave: Treinamento de Resistência. Creatina Quinase. Dano Muscular.

\begin{abstract}
The present study investigated the effect of two resistance training sessions (hypertrophy vs. resistance) on muscle damage 24 and 48 hours post-exercise. Six young men underwent two RT protocols for the entire body, one being a resistance training protocol for hypertrophy (HRT; 75\% 1-RM, 8-12 repetitions) and a resistance training protocol for resistance (RRT; 15\% 1-RM, 50-60 repetitions). Statistically significant differences ( $p<0.05)$ were found in blood CK concentrations between pre- and 24-hour post-exercise values in HRT. There were no differences between groups or between the results of different moments of collection in RRT. It is concluded that the HRT protocol induces a statistically significant increase in CK expression 24 hours after its application and that this expression does not remain high 48 hours after using this protocol. Finally, the TRR protocol showed no differences in blood CK concentrations.
\end{abstract}

Keywords: Resistance Training. Creatine Kinase. Muscle damage.

\section{Resumen}

El presente estudio investigó el efecto de dos sesiones de entrenamiento de resistencia (hipertrofia versus resistencia) sobre los niveles de daño muscular 24 y 48 horas después del ejercicio. Seis hombres jóvenes se sometieron a dos protocolos de RT para todo el cuerpo, uno de ellos es un protocolo de entrenamiento de resistencia para la hipertrofia (HRT; 75\% 1-RM, 8-12 repeticiones) y un protocolo de entrenamiento de resistencia para 
la resistencia (RRT; 15\% 1-RM, 50-60 repeticiones). Se encontraron diferencias estadísticamente significativas $(\mathrm{p}<0.05)$ en las concentraciones de CK en sangre entre los valores previos y de 24 horas posteriores al ejercicio en la TRH. No hubo diferencias entre grupos o entre los resultados de diferentes momentos de recolección en TSR. Se concluye que el protocolo HRT induce un aumento estadísticamente significativo en la expresión de CK 24 horas después de su aplicación y que esta expresión no permanece alta 48 horas después de usar este protocolo. Finalmente, el protocolo TRR no mostró diferencias en las concentraciones de CK en sangre.

Palabras - clave: Entrenamiento de resistencia. Creatina quinasa. Daño muscular.

\section{INTRODUÇÃO}

O treinamento resistido (TR), também conhecido como treinamento com pesos, tornou-se uma das formas mais conhecidas de exercício, sendo destinada tanto à atletas como para praticantes com objetivo à melhoria do condicionamento físico e/ou saúde ${ }^{1}$. Este vem sendo bastante estudado por pesquisadores e apontado como um excelente método no aprimoramento da qualidade de vida de seus praticantes podendo minimizar o surgimento de doenças crônicas degenerativas, diferentes patologias, nas diferentes faixas etárias ${ }^{2,3}$, tais como doenças cardíacas, diabetes, alguns tipos de câncer e patologias osteomioarticulares.

Em função da variedade populacional que pode se beneficiar com o TR, diferentes métodos de treinamento surgem como forma de otimizar de maneira específica, diferentes capacidades físicas, como força, potência, resistência, velocidade e etc ${ }^{1}$. Dentre os múltiplos objetivos buscados pelos praticantes de TR, a hipertrofia muscular certamente se destaca em relação às outras (principalmente quando tratamos da maior parte da população, não-atleta). O treinamento voltado para hipertrofia é caracterizado pelo uso de cargas altas com um número de repetições limitados tradicionalmente entre 8 e 15 repetições por série. Por meio das micro lesões, bem como ativação de vias moleculares ativadas por fatores metabólicos, que ocorre o processo de hipertrofia muscular .

Além do modelo de treinamento amplamente utilizado para hipertrofia, tem se verificado o uso de treinamento de resistência muscular localizada (RML), caracterizado pelo uso de baixas cargas e alto número de repetições por série. Este modelo é usado como base para os outros, justamente por promover o condicionamento fundamental para o trabalho com cargas elevadas, a resistência. A princípio, este modelo de treino se aproximaria mais das atividades cíclicas de baixa-moderada intensidade como corridas e ciclismo, porém no âmbito do TR. O baixo potencial de 
lesões ou microlesões, ou formação de produtos metabólicos inibidores da contração muscular favorece a realização do exercício prolongado, e adaptações que o levem a suportar sucessivas cargas mais elevadas.

Atualmente tem se buscado pesquisar o grau de dano muscular causado pela aplicação de diferentes exercício e protocolos aplicado ao modelo humano e animal ${ }^{5}$. Nesse sentido, a creatina quinase (CK) tem se popularizado como um marcador de dano muscular proveniente da prática de exercício com diferentes perspectivas, seja no desporto de alta competição como nos exercícios orientados para o condicionamento físico e saúde ${ }^{5,6}$.

O pico dessa enzima pode variar de indivíduo para indivíduo, num período compreendido entre $24 \mathrm{hs}$ e $48 \mathrm{hs}$ após a aplicação de uma carga, com valor de intensidade elevado. Esta elevação em sua atividade está relacionada ao tipo de exercício, bem como à relação de volume e intensidade do mesmo ${ }^{7}$. Apesar da sua relação com cargas de alta intensidade no TR, e relação inversa com exercícios com alto volume, não há na literatura, estudos que investiguem sua atividade em esforços de intensidades muito baixas (15\%1-RM) realizados em alto volume (50 - 60 repetições máximas), especialmente quando comparado ao TR voltado para hipertrofia (75\%1-RM; 8-12 repetições máximas).

Assim, o presente estudo teve como objetivo investigar o efeito de duas sessões de TR propostos sob modelos distintos (hipertrofia vs RML de alto volume) sobre a atividade de CK sérica em indivíduos jovens fisicamente ativos.

\section{MATERIAIS E MÉTODOS}

O presente trabalho trata-se de um estudo experimental em crossover. Participaram do presente estudo seis sujeitos do gênero masculino, fisicamente ativos com idade de 21,83 \pm 1,33 anos, $77,94 \pm 18,34 \mathrm{~kg}$ de massa corporal total, $177 \pm 4,3 \mathrm{~cm}$ de estatura e $12,18 \pm 8,3 \%$ de gordura. Todos os participantes eram habituados ao TR por um período mínimo de três meses, não fizeram uso crônico de álcool ou tabaco e tampouco apresentam algum tipo de lesão osteomioarticular. Antes de iniciar o programa de treino, os participantes foram informados de todos os procedimentos de testes invasivos e não invasivos, bem como dos objetivos, riscos e benefícios envolvidos. Todos os participantes tiveram liberdade de abandonar os testes a qualquer momento de acordo com a assinatura do termo de consentimento livre e esclarecido (TCLE) aprovado pelo Comitê de Ética em Pesquisa do Centro de Ciências da Saúde da Universidade Federal da 
Paraíba sob protocolo 17942613.4.0000.5188. Os dados desta pesquisa foram obtidos no Laboratório de Estudos do Treinamento Físico Aplicado ao Desempenho e a Saúde (LETFADS) e também na academia do Departamento de Educação Física do Centro de Ciências da Saúde, na Universidade Federal da Paraíba.

A pesquisa foi realizada em um período de três semanas, em que na primeira semana foram feitas as medidas antropométricas e testes de 1RM para cada um dos exercícios utilizados nos diferentes protocolos. Nas duas semanas subsequentes foram aplicados os protocolos de TR e realizadas as coletas sanguíneas para determinação aguda das concentrações de CK. Os participantes da pesquisa foram submetidos a dois protocolos de TR, um orientado para hipertrofia (TRH) e outro para resistência muscular (TRR), realizados de maneira randomizada. O protocolo para TRH foi composto por três séries de 8-12 repetições máximas com carga de 75\% de 1RM para cada um dos exercícios, com intervalo entre séries de um minuto e meio. Já o TRR foi composto por uma série de 50 a 60 repetições com carga de $15 \%$ de 1RM para cada um dos exercícios, com um minuto de intervalo entre séries. Os exercícios utilizados nos protocolos foram supino plano, puxada por trás da nuca com polia alta, leg hack, extensão de cotovelos com polia alta, flexão de cotovelos com barra reta, mesa flexora, desenvolvimento com barra, flexão plantar e abdominais crunch com pesos. Os voluntários foram orientados a manter os mesmo hábitos diários nos dias que precediam as visitas ao laboratório, bem como não realizar esforços exaustivos. As sessões de treinamento de ambos os modelos levaram um tempo similar para a sua realização ( $\sim 50 \mathrm{~min})$.

O teste de carga máxima (1RM) foi realizado para todos os exercícios na mesma sessão, em ordem randomizada. Estudos prévios demonstraram que não ha interferência na realização de múltiplos exercícios num mesmo dia ${ }^{8}$. Os procedimentos estiveram de acordo com os reportados anteriormente ${ }^{9}$. Após um aquecimento padrão com carga de aproximadamente 50\% 1-RM (predito), os voluntários realizaram cinco tentativas separadas por um intervalo mínimo de cinco minutos. As cargas das tentativas subsequentes foram acrescidas ou reduzidas de acordo com o sucesso da anterior. A execução realizada com a maior carga pelo indivíduo, sem a possibilidade da realização de uma segunda repetição, foi considerada a carga de $100 \%$ de 1-RM. Com o objetivo de aumentar a precisão do teste, estabeleceu-se uma tolerância máxima de 
$1 \mathrm{~kg}$ de diferença entre a intensidade de $100 \%$ de 1-RM e a superior a esta.

Para determinação da expressão de CK foram realizadas três coletas de 0,5ml de sangue do lóbulo da orelha. Para a primeira coleta (PRÉ), os sujeitos apresentaram-se com abstinência de treinamento de pelo menos 48hs. Após 24hs e 48hs da aplicação do protocolo de TRR e TRH, foram realizadas novas coletas sanguíneas. O sangue foi coletado em tubos eppendorf e imediatamente centrifugado durante 30 minutos, a velocidade de 5000rpm para que em seguida o plasma fosse armazenado em temperatura $-20^{\circ} \mathrm{C}$ para posterior análise. A atividade da CK foi determinada pelo método de espectrofotometria, através de kit comercial (CK_NAC UV AA, BioTécnica).

Os dados estão apresentados em média \pm desvio padrão. Após averiguar a normalidade dos dados por meio do teste de Shapiro-Wilk, foi aplicado a estatística paramétrica. A ANOVA one-way foi utilizada para identificar possíveis alterações na atividade de CK nos diferentes momentos de coleta (pré-, 24hs e 48hs após). O nível de significância adotado foi de $5 \%$.

\section{RESULTADOS E DISCUSSÃO}

A tabela 1 apresenta os valores absolutos das cargas referentes à 100\%1RM， 75\%1-RM e 15\%1-RM. Foram encontradas diferenças significativas nos valores de CK do TRH 24h pós-treino vs pré-treino, contudo, 48hs após a sessão de treinamento, este efeito foi eliminado, sem diferenças significativas entre os momentos $48 \mathrm{~h}$ pós-treino vs pré-treino.

Tabela 1. Cargas obtidas nos testes de 1RM e cargas utilizadas nos protocolos de TRH e TRR $(n=6)$.

\begin{tabular}{|c|c|}
\hline Exercícios & Cargas expressas em média e DP \\
\hline & $75 \%$ de $1 \mathrm{RM}$ \\
\hline Mesa flexora & $85,96 \pm 21 \quad 64,47 \pm 15,75 \quad 12,89 \pm 3,15$ \\
\hline Rosca direta & $45,11 \pm 11,7 \quad 33,83 \pm 8,77$ \\
\hline Supino plano & $13,2 \pm 3,61$ \\
\hline Flexão Plantar & $\begin{array}{c}113,34 \pm \quad 85,01 \pm 41,2 \\
54,93\end{array}$ \\
\hline Desenvolvim.* & $55,28 \pm 14,2 \quad 41,16 \pm 10,65 \quad 8,32 \pm 2,08$ \\
\hline Leg Hack & $\begin{array}{c}140,98 \pm \quad 105,73 \pm 39,8 \quad 21,13 \pm 7,94 \\
53,07\end{array}$ \\
\hline Tríceps* & $74,85 \pm 26,2356,14 \pm 19,68 \quad 9,70 \pm 5,48$ \\
\hline Abdominais & $14,23 \pm 6,15 \quad 10,67 \pm 4,61$ \\
\hline Pulley Costas & $90,25 \pm 24,23 \quad 57,09 \pm 31,89 \quad 28,07 \pm 33,91$ \\
\hline \multicolumn{2}{|c|}{$\begin{array}{l}\mathrm{DP}=\text { desvio padrão. }{ }^{*} \text { Desenvolvimento. Tríceps } \\
\text { realizado na polia. Fonte: próprios autores. }\end{array}$} \\
\hline \multicolumn{2}{|r|}{ Por outro lado, o TRR não } \\
\hline \multicolumn{2}{|c|}{ promoveu alterações significativas nos } \\
\hline \multicolumn{2}{|c|}{ níveis de atividade de CK em nenhum } \\
\hline \multicolumn{2}{|c|}{ dos momentos avaliados. Os resultados } \\
\hline \multicolumn{2}{|c|}{ da atividade de $\mathrm{CK}$ nos diferentes } \\
\hline momentos & s para cada modelo de \\
\hline \multicolumn{2}{|c|}{ treinamento estão identificados na tabela } \\
\hline 2. & \\
\hline
\end{tabular}

\section{CONCLUSÃO}

De acordo com os resultados, podemos concluir que o TR realizado sob baixa intensidade e alto volume, não 
é capaz de promover significativas elevações na atividade de CK sérica pós exercício, indicando um menor efeito em termos de micro lesões no tecido muscular. Por outro lado, o TRH, promoveu aumento na atividade de CK 24hs pós-treino. Efeito este que foi significativamente reduzido no momento 48hs pós-treino, sugerindo que neste momento, uma nova sessão de treino poderia ser implementada para o mesmo grupo muscular.

Tabela 2. Expressão sanguínea de creatina quinase (CK) em treinamento resistido de hipertrofia (TRH) e resistência (TRR) nos Momentos PRÉ, 24hs e 48hs após exercício ( $\mathrm{n}=$ $6)$.

\begin{tabular}{cccc}
\hline & PRÉ & 24hs & 48hs \\
\hline TRH & $129,2 \pm$ & $315,16 \pm$ & $223,18 \pm$ \\
& 58,26 & $181,34^{*}$ & $133,43^{* *}$ \\
TRR & $167,83 \pm$ & $233,59 \pm$ & $192,34 \pm$ \\
& 94,82 & 153,78 & 121,30 \\
\hline
\end{tabular}

Valores em média \pm desvio padrão da expressão de CK em (IU/l). * diferença estatisticamente significativa em relação a PRE do TRH. * diferença estatisticamente significativa em relação a 24H do TRH;

\section{REFERENCIAS / REFERENCES}

1. Kraemer WJ, Ratamess NA, French DN. Resistance training for health and performance. Current sports medicine reports. 2002.

2. Fleck , SJ; Kraemer W. Fundamentos do Treinamento de Força Muscular. $2^{\circ}$ ed Porto Alegre Artmed. 1999;

3. American College of Sports Medicine. American College of Sports Medicine position stand. Progression models in resistance training for healthy adults. Med Sci Sports Exerc. 2009;
4. Schoenfeld BJ. The mechanisms of muscle hypertrophy and their application to resistance training. Journal of Strength and Conditioning Research. 2010 .

5. Brancaccio P, Maffulli N, Limongelli FM. Creatine kinase monitoring in sport medicine. $\mathrm{Br}$ Med Bull. 2007;81-82(1):209-30.

6. de Araujo GG, Gobatto CA, Hirata RDC, Hirata MH, Cavaglieri CR, Verlengia R. Respostas fisiológicas para detectar o overtraining. Rev da Educ Física. 2008;19(2):275-89.

7. Mougios V. Reference intervals for serum creatine kinase in athletes. $\mathrm{Br} \mathrm{J}$ Sports Med. 2007;

8. Neto JC, Cedin L, Dato CC, Perez SA, Baldissera V. A Single Session of Testing for One Repetition Maximum (1RM) with Eight Exercises is Trustworthy José. J Exerc Physiol. 2015;18(3):74-80.

9. Carlos de Oliveira J, Baldissera V, Gustavo Simões H, Paula de Aguiar A, Henrique Silva Marques de Azevedo P, Aparecida Franco de Oliveira Poian P, et al. Identificação do limiar de lactato e limiar glicêmico em exercícios resistidos ARTIGO ORIGINAL. Rev Bras Med Esporte [Internet]. 2006;12(6):333-8. Available from: http://www.scielo.br/pdf/\%0D/rbme/v12 n6/a07v12n6.pdf

10. Brancaccio P, Maffulli N, Buonauro R, Limongelli FM. Serum Enzyme Monitoring in Sports Medicine. Clinics in Sports Medicine. 2008.

11. Clarkson PM, Hubal MJ. Exerciseinduced muscle damage in humans. In: American Journal of Physical Medicine and Rehabilitation. 2002.

12. Carmona G, Guerrero M, Cussó R, Padullés JM, Moras G, Lloret M, et al. 
Muscle enzyme and fiber type-specific sarcomere protein increases in serum after inertial concentric-eccentric exercise. Scand J Med Sci Sport. 2015;

13. Noakes TD. Effect of Exercise on Serum Enzyme Activities in Humans. Sports Medicine: An International Journal of Applied Medicine and Science in Sport and Exercise. 1987.

14. Uchida MC, Nosaka K, Ugrinowitsch C, Yamashita A, Martins E, Moriscot A, et al. Effect of bench press exercise intensity on muscle soreness and inflammatory mediators. J Sports Sci. 2009 .
Informações do artigo / Information of this article:

Recebido: 10/11/2019

Aprovado: 14/11/2019

Publicado: 06/05/2020

Received: 10/11/2019

Approved: 14/11/2019

Published: 06/05/2020

Claudio Luiz de Souza Meireles

ORCID: 0000-0002-3436-1870.

Como citar esse artigo / How to cite this article:

Meireles, C. L S; Paiva, R. R.; Forte, L. D. M. Respostas agudas e tardias da creatina quinase após duas configurações distintas de treinamento resistido. Arq. Bras. Ed. Fís., Tocantinópolis, v. 3, n. 1, Jan./Jul., p. 15 - 21, 2019. 